EPJ Web of Conferences 106, 02010 (2016)

DOI: $10.1051 /$ epjconf/201610602010

(C) Owned by the authors, published by EDP Sciences, 2016

\title{
Reactor Dosimetry Aspects of the Service Life Extension of the Hungarian Paks NPP
}

\author{
Eva M. Zsolnay ${ }^{1}$, Szabolcs Czifrus ${ }^{1, a}$, Sándor Fehér ${ }^{1}$, Gábor Hordósy ${ }^{2}$, András Keresztúri ${ }^{2}$, Norbert \\ $\mathrm{Kresz}^{3}$, and Ferenc Oszvald ${ }^{3}$ \\ ${ }^{1}$ Institute of Nuclear Techniques, Budapest University of Technology and Economics, Múegyetem \\ rkp. 9, 1111 Budapest, Hungary \\ ${ }^{2}$ Hungarian Academy of Sciences, Centre for Energy Research, P.O.B. 49, 1523 Budapest, Hungary \\ ${ }^{3}$ Paks Nuclear Power Plant Ltd. P.O. B.71, 7031 Paks, Hungary
}

\begin{abstract}
The service life of the Hungarian Paks Nuclear Power Plant (NPP) will be extended from the originally planned 30 years to 50 years. To improve the reliability of the results obtained in frame of the old reactor pressure vessel (RPV) surveillance programme, new methods have been developed, and based on them, the old exposition data have been re-evaluated for all the four reactor units. At the same time, a new RPV surveillance programme has been developed and introduced, and long term irradiations have been performed to determine the radiation damage of the surveillance specimens due to the high fast neutron exposition. Neutron transport calculations have been performed with a validated neutron transport code system to determine the fast neutron exposition of the RPVs during the extended service life. The cavity dosimetry is in the introductory phase. This paper presents the new developments in the field of the RPV surveillance dosimetry and summarises the results obtained. According to the results the service life of the NPP can safely be extended for the planned 50 years.
\end{abstract}

\section{Introduction}

The Paks Nuclear Power Plant (NPP) comprises four VVER-440/213 type reactor units with an original nominal thermal power of 1375 MW. The first unit started energy production in 1984, while the other ones were put into operation gradually until 1987. Starting from 2005, the power of the reactors has been gradually increased to the present $1485 \mathrm{MW}$, which is $8 \%$ higher than the original nominal power.

The service life of the nuclear power plant was originally planned for 30 years, but - as the condition of the reactors and other important components of the power plant (according to the corresponding surveillance investigations) seemed to be suitable for a longer operation - it has been decided to increase the service life to 50 years. Naturally, the realization of this plan involved a number of safety aspects: the condition of all the nuclear power plant components had to be investigated and it had to be proved with a high reliability that their state insures the safe operation of the NPP until the end of the extended service

\footnotetext{
${ }^{\text {a }}$ Corresponding author: czifrus@reak.bme.hu
}

This is an Open Access article distributed under the terms of the Creative Commons Attribution License 2.0, which permits unrestricted use, distribution, and reproduction in any medium, provided the original work is properly cited. 
life. Therefore, the condition of the reactor pressure vessel (RPV) has to be monitored continuously during the whole service life of the NPP.

The reactor dosimetry part of the original RPV surveillance programme of the Paks NPP suffered from several disadvantages (un-oriented positioning of the neutron monitors in the surveillance capsules, uncertainty in their distance from the active core, etc.), which caused a large uncertainty in determination of their exposure. On the other hand, due to the large lead factor ( $L F \sim 12$ at the neutron fluence rate maximum due to the positioning of the surveillance capsules of the VVER-440 reactors at the outer side of the core barrel) the original surveillance chains had to be withdrawn four years after starting the reactor operation. Therefore, at the beginning of the 1990s, a new RPV surveillance programme was developed, and will be operated until the end of the original (30 years) service life of the reactors. At the same time, for the reactor units operating already in frame of their extended service life, a newer RPV surveillance programme has been developed and started for the reactor unit No. 1.

For the reliable estimation of the lifetime of the RPV the following actions have been made in the field of the reactor dosimetry:

- New methods have been developed and the results of the old surveillance programme have been reevaluated to decrease the uncertainty of the fast neutron exposure of the material testing specimens in the surveillance capsules.

- A new RPV surveillance programme was developed in a way that the irradiation results should show the exposure of the RPV after the planned extended service life with a better reliability than before. This type of RPV surveillance irradiations have been performed in all the four reactor units.

- Neutron transport calculations have been performed using the KARATE-MCNP code system [1,2] to determine the fast neutron exposure of the RPV wall during the operation of the reactors.

- Sensitivity analysis was developed and performed to determine the uncertainty of the neutron transport calculations.

- The ex-vessel ("cavity") dosimetry is under introduction in co-operation with the Skoda Works (several irradiations have already been performed at the outer wall of the RPV and have been evaluated, others are in progress).

- Neutron transport calculations were performed based on the new reactor core configuration to be used during the extended service life, and the fast neutron exposure of the RPV was estimated over the planned 50 years service life of the NPP.

This paper presents the developed new methods and reactor dosimetry results and, due to the efforts listed above, indications on the fast neutron exposure of the RPV during the extended service life of the NPP. The pressurized thermal shock (PTS) analysis performed to determine the lifetime of the RPVs is based on these reactor dosimetry results.

\section{Actions in the Field of Reactor Dosimetry for the Service Life Extension}

\subsection{Improving the Uncertainties of the Reactor Dosimetry Results in the Old RPV Surveillance Programme}

The original ("old") surveillance programme of the reactor pressure vessels of the VVER-440 type nuclear power plants, as developed by the constructor, had several shortcomings, which resulted in a large uncertainty in the reactor dosimetry results. The neutron monitors were located in front of the surveillance specimens, and the specimen-neutron monitor sets were situated in irradiation capsules (see Fig. 1). The orientation of the monitor-specimen sets in the capsules was not recorded. Furthermore, the capsules in the irradiation channel could randomly spin to an undefined position relative to the direction of the reactor core. Thus the geometry of the specimen-neutron monitor set became undefined 


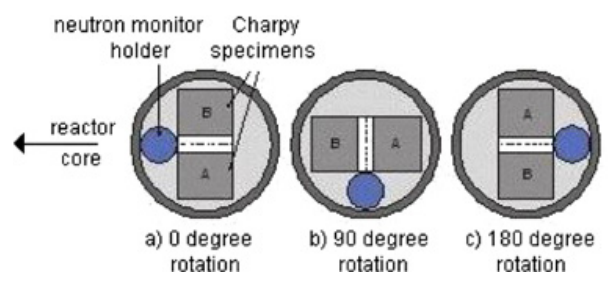

Figure 1. Geometrical positions of the specimens and of the neutron monitors in the irradiation capsule in three different cases of rotation relative to the direction of the reactor core (old RPV surveillance programme).

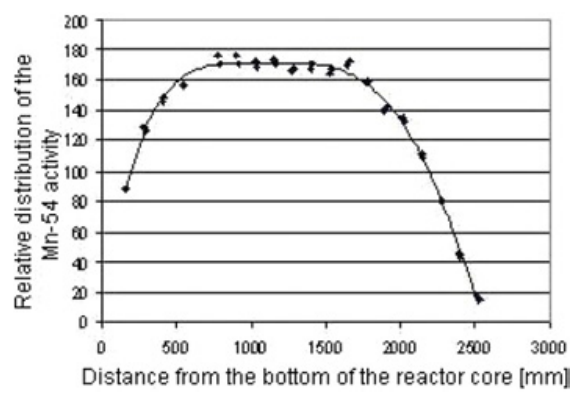

Figure 2. Relative ${ }^{54} \mathrm{Mn}$ activity values measured on the Charpy specimens and the polynomial of $5^{\text {th }}$ order fitted to the measurement points (Paks NPP, reactor unit 2, operation cycles 1-3).

during the irradiation, relatively to the active core. Depending on whether the neutron monitors were in front or behind the specimens, their distance from the reactor core in the direction of the flux gradient could differ by as high as $1 \mathrm{~cm}$. In addition, due to the construction of the irradiation channels, the surveillance chains had a $5 \mathrm{~mm}$ horizontal positioning uncertainty in the irradiation channel. All these geometrical uncertaintes could then be added, thus increasing the uncertainty in the value of the fast neutron exposition derived from the reactor dosimetry investigations [3].

The first step in handling this problem was to determine whether the rotation of the surveillance capsules was random. The question was answered with the aid of the retrospective dosimetry $[4,5]$. Samples were taken from ten Charpy specimen pairs (irradiated in two different reactor cycles) from seven different points along the surface of the fracture. Then the relative specific ${ }^{54} \mathrm{Mn}$ activity (deriving from the reaction $\left.{ }^{54} \mathrm{Fe}(\mathrm{n}, \mathrm{p})^{54} \mathrm{Mn}\right)$ of the samples was measured and compared with the corresponding results of MCNP model calculations [5]. The outcome of the procedure demonstrated that the rotation of the irradiation capsules relative to the direction of the reactor core could be considered random. Monte Carlo calculations have shown [5] that due to all the above mentioned factors, the fast neutron $(\mathrm{E}>0.5 \mathrm{MeV}$ ) exposition of the neutron monitors could vary up to $30-40 \%$.

To overcome these problems, in frame of the reactor dosimetry studies of the RPV surveillance programme, a special method was developed to evaluate the responses of the neutron monitors [6, 7]. Supposing that the ${ }^{54} \mathrm{Mn}$ activity of the specimens was proportional to the axial distribution of the fast neutron fluence rate irradiating the corresponding specimen pairs, the axial distribution of the (relative) ${ }^{54} \mathrm{Mn}$ activity was measured on four sides of the specimens in the vicinity of their geometrical center. The relative ${ }^{54} \mathrm{Mn}$ activity values obtained in this way were averaged over the specimen pair situated in a surveillance capsule. Then a polynomial of $5^{\text {th }}$ order was fitted on to the points representing the axial ${ }^{54} \mathrm{Mn}$ activity distribution of the specimens (Fig. 2; the uncertainty of the measured ${ }^{54} \mathrm{Mn}$ activity values was 4\%) and the curve was shifted to fit to the measured reaction rates (Fig. 3) of the neutron monitors [7] (the uncertainty of the measured reaction rates of the reaction ${ }^{93} \mathrm{Nb}\left(\mathrm{n}, \mathrm{n}^{\prime}\right)$ 


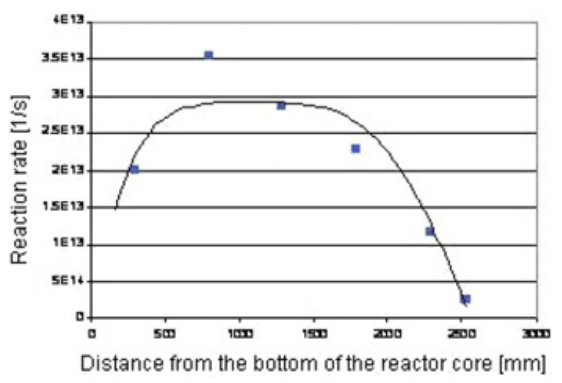

Figure 3. The measured reaction rates for the reaction ${ }^{93} \mathrm{Nb}\left(\mathrm{n}, \mathrm{n}^{\prime}\right)^{94} \mathrm{Nb}$, and the $5^{\text {th }}$ order polynomial representing the relative ${ }^{54} \mathrm{Mn}$ activity distribution measured on the Charpy specimens (Paks NPP, reactor unit 2, operation cycles 1-3).

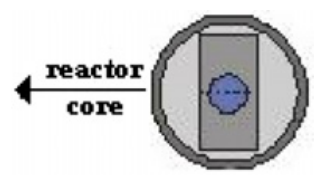

Figure 4. Geometrical position of the specimens and neutron monitors in the irradiation capsule in frame of the new RPV surveillance programme.

shown in Fig. 3 is about 6\%). In this way the reaction rates of the neutron monitors irradiated in unknown geometrical circumstances were fitted to the fast neutron fluence rate distribution irradiating the surveillance specimens. These "fitted" reaction rates were then used further on in the calculations (neutron spectrum adjustment and determination of exposition parameters).

The reactor dosimetry results obtained in frame of the original reactor surveillance programme were then re-evaluted for all the four reactor units (see e.g. Refs. [6] and [7]). The uncertainty of the neutron fluence rates obtained this way was between $9.5 \%$ and $12.5 \%[6,7]$, instead of the former 30-40\%.

The Charpy specimens for fracture mechanics analyses are irradiated in the region of the maximum neutron fluence rate, where the gradient of the fluence rate is very small. The data evaluation of fracture mechanics is based on averaging the results of 4-6 surveillance capsules. If we follow the same procedure by averaging the fast neutron fluence values of 4-6 capsules (irradiated in the region of maximum neutron fluence rate), the uncertainty in the fast neutron exposition of the specimens determined in the way described above - can be significantly decreased.

\subsection{Development and Introduction of a New RPV Surveillance Programme - Reactor Dosimetry Results}

In frame of the new RPV surveillance programme elaborated at the beginning of the 1990s, new specimens and new neutron monitor sets were inserted in the irradiation channels [8]. As the neutron monitors in frame of this new programme were placed on the top of the specimens (in the geometrical axis, see Fig. 4), they measure the axial distribution of the neutron fluence rate at the mid position of the two specimens in the capsule considered, independently of the rotation of the capsule. The evaluation of the neutron monitor responses requires now the application of two different methods, depending on the axial positioning of the irradiation capsules.

As in the maximum region of the axial fast neutron fluence rate $(800 \mathrm{~mm}-1800 \mathrm{~mm}$ from the bottom of the reactor core), where the gradient of the fluence rate is small, the average of the exposition of the two specimens can be well approximated by the exposition of the neutron monitors situated in the 


\section{$15^{\text {th }}$ ISRD}

Table 1. Average fast neutron fluence rate $(E>0.5 \mathrm{MeV})$ irradiating the RPVsurveillance specimens in the region of the neutron fluence rate maximum, in frame of the new RPV surveillance programme.

\begin{tabular}{|c|c|c|c|c|}
\hline $\begin{array}{c}\text { Reactor } \\
\text { unit }\end{array}$ & $\begin{array}{c}\text { Reactor } \\
\text { cycle }\end{array}$ & $\begin{array}{c}\text { Date of } \\
\text { irradiation }\end{array}$ & $\begin{array}{c}\text { Measured } \boldsymbol{\varphi}^{\text {av }}(\mathbf{E}>0.5 \\
\mathbf{M e V}) \\
\left(\mathbf{c m}^{-2} \mathbf{s}^{-\mathbf{1}}\right)\end{array}$ & $\begin{array}{c}\text { No. of capsules } \\
\text { in the averaging }\end{array}$ \\
\hline 1 & $12-16$ & $1994-1999$ & $2.467 \mathrm{E} 12 \pm 4.9 \%$ & 4 \\
\hline 2 & $12-16$ & $1995-2000$ & $2.615 \mathrm{E} 12 \pm 5.8 \%$ & 2 \\
\hline 3 & $11-15$ & $1996-2001$ & $2.517 \mathrm{E} 12 \pm 5.0 \%$ & 4 \\
\hline 4 & $7-11$ & $1993-1998$ & $3.019 \mathrm{E} 12 \pm 10.0 \%$ & 1 \\
\hline
\end{tabular}

same capsule [5]. In this region the fast neutron fluence rate change is only $10 \%-12 \%$. Due to the geometrical positioning of the monitor set $(29 \mathrm{~mm}$ above the axial center of the specimens), the fast neutron exposition of the specimens differs from that of the neutron monitors on the average only by $1.7 \%$ [5]. Therefore, the response of the neutron monitors can be directly used for determining the exposition of the specimen pairs in the surveillance capsules considered.

In the region outside the axial maximum of the fast neutron fluence rate, where the gradient of the fluence rate is large (see e.g. Fig. 4), the fast neutron exposition of the neutron monitors can not be considered equal with that of the specimens. Therefore, in this case for the evaluation of the fast neutron exposition of the surveillance specimens the axial distribution of the fast neutron fluence rate should be known. Again, two methods can be followed in this case: experiments or neutron transport calculations. In the first case - if the irradiation time is not longer than 1-2 years - the ${ }^{54} \mathrm{Mn}$ activity distribution of the irradiated specimens can be measured as described in the case of the old surveillance programme. Then the relative axial fast neutron fluence rate distribution obtained can be shifted to fit the responses of the neutron monitors. The other experimental possibility is to evaluate the responses of the neutron monitor sets as the function of their axial coordinates, and in this way derive the axial fast neutron fluence rate distribution. In both cases a polynomial has to be fitted to the data deriving from the measurements and in knowledge of the corresponding coordinates, the fast neutron exposition of the specimens can be determined.

The other method for determining the axial fast neutron fluence rate distribution along the whole surveillance chain is to perform neutron transport calculations by a validated neutron transport code. The KARATE-MCNP code system was developed for this purpose (see in the next subsection) [1, 2, 9]. The results of the neutron transport calculations can then be compared with the corresponding experimental data, and applied further on in the dosimetry calculations (examples for the results of the neutron transport calculations can be found in the next subsection).

In frame of the new RPV surveillance programme several irradiations were performed and evaluated for monitoring the exposition of the reactor pressure vessels during the originally planned 30 years service life of the NPP (see e.g. [6, 7]). The uncertainty of the fast neutron exposition of the RPV specimens determined in the way described above was in the vicinity of $10 \%$. In order to establish the planned service life extension of the NPP to 50 years, long term RPV surveillance irradiations were performed in all the four reactor units [7, 10-12]. Due to the large lead factor (LF $\sim 12$ at the neutron fluence rate maximum), 5-year-long irradiations in the positions of the fluence rate maximum give a good estimate of the fast neutron exposition obtained by the reactor pressure vessels during $\sim 60$ years of reactor operation. The reactor dosimetry results derived from this type of irradiations can be seen in Table 1 [12]. The neutron fluence rate values present in the table are the average values obtained from the responses of several detector sets situated in the region of the fluence rate maximum, and irradiated for five years.

It can be seen that in the case of the reactor units Nos. 1, 2 and 3, very similar neutron fluence rate values were obtained. The corresponding neutron fluence rates obtained in the case of the reactor unit No. 4 are about $20 \%$ higher than the ones mentioned before. The reason of this deviation is partly due 
to the fact that in the case of the reactor units Nos. 1, 2 and 3, low leakage cores were applied during the irradiation, while in the case of reactor unit No. 4 only partially low leakage cores were applied. Also these data show clearly the effect of the low leakage core on the exposition of the RPV. The neutron fluences obtained from these data combined with the results of the fracture mechanics analyses can give information on the condition of the RPVs after the extended service life of the NPP.

\subsection{Neutron Transport Calculations}

Neutron transport calculations were made to determine the fast neutron exposition of the RPVs of the different reactor units of the Paks NPP. As mentioned above, the calculations were made using the KARATE-MCNP code system developed at the Centre for Energy Research of the Hungarian Academy of Sciences [1,2]. In order to take into account the influence of the various core loads and operational parameters, the neutron source was determined on the boundaries of the reactor core with the aid of the KARATE reactor core design code. The neutron transport outside the core was followed by the MCNP Monte Carlo code [13]. In order to accuratelly predict the neutron fluence irradiating the RPV, changes of the neutron source in the reactor core were followed with sufficient frequency.

Sensitivity analysis was performed, and from the results the uncertainty of the calculated fast neutron fluence rate at the inner surface of the RPV was estimated to be $10 \%$. This value contains the uncertainties due to the Monte Carlo calculations, technological uncertainties (geometrical and density data) and nuclear data.

Prior to the start of the calculations, the code system was validated in the framework of the REDOS project [14] in reference neutron fields of the LR-0 reactor, constituting VVER-440 and VVER-1000 mock-up cores [1], and by comparison with in situ measurements at the RPV surveillance positions of the different reactor units of the Paks NPP [15]. In both cases, good agreement was obtained between the calculated and experimental data. The validation procedure using the RPVsurveillance data of the Paks NPP involved the comparison of the measured and calculated reaction rate values obtained from 91 irradiated activation detectors from two reactor units. The deviation between the measured and calculated reaction rate values was less than the uncertainty originating from the measurements and the calculations.

Several calculations - comprising different irradiation cycles - were made for determining the fast neutron exposition of the irradiated RPV surveillance specimens and of the reactor pressure vessels of all the four reactor units [15]. The calculated fast neutron fluence values were then used in the PTS analysis of the radiation damage investigations.

On the other hand, the performed neutron transport calculations involved the determination of the total fast neutron exposure $(\mathrm{E}>0.5 \mathrm{MeV})$ of the RPVs for the end of the 30 years service life and for the end of the extended (50 years) service life of the NPP $[15,16]$. The results have yielded a fast neutron fluence value of (2.6-3.6) $10^{20} \mathrm{~cm}^{-2}$ for the 50 years exposition of the RPVs of the NPP in the region of the neutron fluence rate maximum, strongly depending on the assumptions on the future core configurations. Calculations for irradiation periods longer than the extended 50 years service life have also been performed [9], and the results obtained were used in the PTS analysis.

\subsection{Introduction of Cavity Dosimetry}

The application of the cavity dosimetry can supply valuable information: experimental data obtained from the measurement and evaluation of the activities of the neutron monitors irradiated in the cavity can be used to determine the fast neutron exposition of the outer wall of the RPV in several important geometrical positions (e.g. in the position of the azimuthal and axial fast neutron fluence rate maximum, and in the position of the important welding Nos. 5/6 located in the height of the active core, etc.), and for the validation of the neutron transport calculations. 


\section{$15^{\text {th }}$ ISRD}

The cavity dosimetry investigations at the Paks NPP started in 2007 and they are in progress also today. The first irradiations were made in cooperation with the SKODA Works on the reactor unit 3 $[17,18]$. Three irradiations (at reactor power values of $1375 \mathrm{MW}, 1430 \mathrm{MW}$ and $1485 \mathrm{MW}$ ) were performed in course of increasing the original reactor power total by $8 \%$. The irradiations lasted for one year. In these experiments neutron monitors both of the SKODA Works and of the Paks NPP were irradiated and evaluated, and besides the neutron spectrum measurements also the azimuthal and axial fast neutron fluence rate distribution was determined.

Similar irradiation was made during the cycle No. 28 of the reactor unit 2 of the Paks NPP [19], and also further cavity irradiations are in progress. These latter ones are performed by the Paks NPP alone. In the mean time the power of all the reactor units has been increased to $108 \%$ of the original value. At the same time, parallel with the cavity experiments, long term (4 years) irradiations of RPV sureveillance chains (containing specimens and neutron monitors) have been going on in the surveillance positions of the corresponding reactor units. The evaluation of the experimental data has been continuosly going on, and the final conlusions in case of the different reactor units will be drawn when all the results of the irradiations planned for a reactor unit will be available. From the data obtained from the long term RPV surveillance irradiations - combined with the results of earlier similar irradiations - also the "flux effect" of the radiation damage will be investigated. This action will be made in frame of the newer RPV surveillance programme running in frame of the extended service life of the NPP.

\section{Conclusions}

From the results described above, the following conclusions can be drawn.

- Due to the new methods introduced and to the new RPV surveillance programme the uncertainty of the exposition of the RPV specimens has been reduced from the former (30-40)\% to about $10 \%$.

- Averaging the neutron fluence rates in the region of their maximum value resulted in a significant reduction in the uncertainty of the fast neutron exposition of the RPV specimens.

- The results of the neutron transport calculations have been compared with the corresponding experimental data, and a good agreement between the two data sets was found (the deviation between the two data sets was smaller than one standard deviation of the considered values).

- The introduction of the cavity dosimetry will improve our knowledge about the radiation damage of the RPVs, gives a meaningful contribution to the validation of the neutron transport code system applied, and gives a tool to easily follow the effect of the core configuration changes on the exposition of the RPV.

- Based on the data obtained from the long term RPV surveillance irradiations, the "flux effect" of the radiation damage will also be studied. This action will be performed in course of the newer RPV surveillance programme, running in frame of the extended service life of the NPP.

- The results of the PTS analysis considering the radiation damage investigations based on the reactor dosimetry data derived in the way described above have shown that all the RPVs of the Paks NPP can safely be operated over 60 years [19]. This period is longer than the extended 50 years service life of the NPP.

\section{References}

[1] G. Hordósy, Gy Hegyi, A. Keresztúri, Cs. Maráczy, E. Temesvári, P. Vértes, É. Zsolnay: Pressure vessel calculations for VVER-440 reactors. Radiation Protection Dosimetry, 115, Page 100-103, 2005 
[2] A. Keresztúri, Gy. Hegyi, L. Korpás, Cs. Maráczy, M. Makai, M. Telbisz: General features and validation of the recent KARATE-440 code system. Int. J. of Nuclear Energy Science and Technology, Vol.5, No. 3, pp. 207-238. 2010

[3] E. M. Zsolnay, Sz. Czifrus, S. Fehér and F. Oszvald: Method for decreasing the uncertainty in reactor dosimetry results due to the undefined positioning of the surveillance capsules at the VVER440 NPP reactors. Paper presented at the 12th ISRD, Gatlinburg, USA, 2005 (Paper not published)

[4] E. M. Zsolnay, S. Feher, Sz. Czifrus, G. Hordosy: Retrospective dosimetry on the Paks RPVs. Report in Hungarian. BME-NTI-261/2002. Budapest, January 2002

[5] E. M. Zsolnay, S. Feher, Sz. Czifrus: The uncertainty of the service life assessment of the reactor pressure vessel. Report in Hungarian. BME-NTI-273/2003-2004, Budapest, May 2004

[6] E. M. Zsolnay, S. Feher, Sz. Czifrus: Improving the accuracy of the results of the reactor dosimetry investigations on the exposure of the RPVs of the Paks NPP ( I.). Report in Hungarian. BME-NTI-264/2002. Budapest, December 2002

[7] E. M. Zsolnay, Sz. Czifrus, S. Feher: Improving the accuracy of the results of the reactor dosimetry investigations on the exposure of the RPVs of the Paks NPP (II.). Report in Hungarian. BME-NTI-287/2004-2005. Budapest, February 2005

[8] E. M. Zsolnay, E. J. Szondi: Recommendation on the reactor dosimetry investigations to be performed in frame of the new RPV surveillance programme. Report in Hungarian. BME-NTI-201/1991. Budapest, November 1991

[9] G. Hordósy, A. Keresztúri, Cs. Maráczi, E. Temesvári, Gy. Hegyi, É. M. Zsolnay: Pressutre vessel fluence calculations for the power uprate and the lifetime extension. Paper to be presented at the $15^{\text {Th }}$ ISRD, Aix en Provance, 18-23 May 2014

[10] E. M. Zsolnay, Sz.Czifrus: Evaluation of the responses of the neutron monitors irradiated during the cycles 12-16 (1994-1999) of the unit 1 of the Paks nuclear power plant, and determination of the fast neutron exposure of the specimens to the service life extension of the NPP. Report in Hungarian. BME-NTI-311/2005. Budapest, December 2005

[11] E. M. Zsolnay, Sz. Czifrus, D. Bódizs: Evaluation of the responses of neutron monitors (Paks NPP reactor unit 2, cycles 12-16, 1995-2000) to the service life extension of the nuclear power plant, and solution of other kinds of problems for the NPP. Report in Hungarian: BME-NTI-365/2006. Budapest, November 2006

[12] E. M. Zsolnay, Sz. Czifrus: Development of the investigation method and evaluation of the response of the RPV surveillance neutron monitors for the service life extension of the NPP (Paks NPP, reactor unit 3, cycles 11.-15., 1966-2001). Report in Hungarian BME-NTI-409/2007. Budapest, December 2007

[13] MCNP - A General Monte Carlo N-Particle Transport Code, Version 5, Volume I: Overview and Theory, LA-UR-03-1987, Volume II: User's Guide, LA-CP-03-0245, Volume III. Developer's Guide, LA-CP-03-0284

[14] B. Boehmer, Ballesteros, J. Konheiser, B. Ošmera, J. Kyncl, G. Hordósy, A., Keresztúri, S. Belousov, K. Ilieva, D. Kirilova, M. Mitev, V. Smutný, E. Polke, S. Zaritsky, C. Töre, P. Ortego: Deep Penetration Benchmarking Conclusions And Recommendations. Redos/R(07)/ 2004 / issue 1

[15] Gábor Hordósy, György Hegyi: Reactor Physical Calculations for the Study of the Pressure Vessel Radiation Damage of the Paks Nuclear Power Plant. Report in Hungarian. AEKI-RAL2004/752/02/M2, Budapest 2008 (in Hungarian)

[16] G. Hordósy, Gy. Hegyi, Cs. Maráczy: Repetition of the KARATE-MCNP neutron fluence calculation for the fuel with Gadolinium. Report in Hungarian. AEKI-RAL-2009/ 745/04/M1

[17] E. M. Zsolnay, Sz. Czifrus, S. Fehér: Development of the method for evaluation of the responses of neutron monitors irradiated for 16 years in the reactor unit 1 , and irradiated in the cavity of 


$$
15^{\text {th }} \text { ISRD }
$$

the reactor unit 3, during the reactor cycle between 2007-2008 (cycle 23). Report in Hungarian. BME-NTI-505/2009. Budapest, March 2010

[18] E. M. Zsolnay, Sz. Czifrus, D. Kis: Development of method for evaluation of the responses of neutron monitors irradiated in the cavity of the reactor unit 3 of the Paks NPP, at $104 \%$ and $108 \%$ reactor powers, and based on it, determination of the exposition data. Report in Hngarian. BME-NTI-534/2011. Budapest, June 2011

[19] E. M. Zsolnay, Sz. Czifrus, D. Kis: Evaluation of the responses of neutron monitors irradiated in the cavity of the reactor unit 2 of the Paks NPP, during the reactor cycle 28. Report in Hungarian. BME-NTI-643/2014. Budapest, April 2014

[20] P. Trampus, G. Bóna, J. Elter, T. Fekete, A. Keresztúri, S. Rátkai: Pressurized Thermal Shock Analysis, Paks NPP Units 1-4. Summary Report. EJR No: 000000A00212 OKA, Paks, 2010 